Research Article

\title{
Comparative Study of Coagulation Profile in Normal Pregnant Women, Pregnant Women at High Risk, Normal Non-Pregnant Healthy Women and Pregnancy Outcome
}

\author{
Shalini Shakarwal', Ragini Mehrotra ${ }^{2}$, Meena Dayal $^{3}$ \\ ${ }^{1}$ Assistant Professor, Department of Obstetrics \& Gynaecology, Maulana Azad Medical College, New Delhi, India. \\ 2,3Professor, Department of Obstetrics \& Gynaecology, M.L.N. Medical College Allahabad, Uttar Pradesd, India. \\ DOI: https://doi.org/10.24321/2349.7181.202010
}

I $\quad \mathbf{N} \quad \mathbf{F} \quad \mathbf{O}$

Corresponding Author:

Shalini Shakarwal, Department of Obstetrics \& Gynaecology, Maulana Azad Medical College, New Delhi, India.

E-mail Id:

shakarwal2001@gmail.com

Orcid Id:

https://orcid.org/0000-0002-2648-0183

How to cite this article:

Shakarwal S, Mehrotra R, Dayal M. Comparative Study of Coagulation Profile in Normal Pregnant Women, Pregnant Women at High Risk, Normal Non-Pregnant Healthy Women and Pregnancy Outcome. J Adv Res Med 2020; 7(3): 1-6.

Date of Submission: 2020-12-01

Date of Acceptance: 2020-12-09

\section{$\begin{array}{llllllllllllll}\mathbf{A} & \mathbf{B} & \mathbf{S} & \mathbf{T} & \mathbf{R} & \mathbf{A} & \mathbf{C} & \mathbf{T}\end{array}$}

Aims and Objective: To study and compare coagulation profile in normal pregnancy, pregnant women at high risk, non-pregnant women and pregnancy outcome.

Method: This comparative prospective study was done in tertiary healthy care centre of north India for over period of one year.

Result: Total 230 cases were taken, out of which 222 antenatal cases were unbooked cases with no antenatal visits along with 8 non-pregnant healthy women. Cases were further divided into three groups of nonpregnant women, normal pregnant women and pregnant women at high risk. All groups were compared for derangement of coagulation profile and pregnancy outcome in terms of adversity.

In normal pregnant women (Group-1), there were 2 cases (94.4\%) of deranged coagulation with isolated thrombocytopenia. In pregnant women at high risk (Group-2), 31 cases (16.6\%) were having deranged coagulation out of which maximum cases were of eclampsia- preeclampsia spectrum (eclampsia and HELLP syndrome) followed by anaemia, placental abruption and placenta previa. In terms of adverse pregnancy outcome, maximum mortality was again in ecalmpsia and HELLP syndrome cases. In adverse perinatal outcome along with eclampsia and HELLP syndrome, preterm labour and FGR was a significant factor.

Conclusion: Hypertensive disorders of pregnancy remain the main cause of deranged coagulation and adverse outcome in high risk pregnancy group along with anaemia and liver disease.

Keywords: Coagulation Profile, Eclampsia, FGR-Fetal Growth Retardation, HELLP- Haemolysis, Elevated Liver Enzymes, Low Platelets 


\section{Introduction}

Disorders of haemostasis, haemorrhage and thromboembolism constitute being major hazards of pregnancy. The coagulation and fibrinolytic enzyme system play an essential role in maintaining the integrity of the vascular tree. Normal pregnancy is hypercoaguble state with six-fold higher chance of thromboembolism than normal population. Pregnancy normally induces increase in the concentration of coagulation factors. ${ }^{1}$ These include increases in a number of clotting factors (I, II, VII, VIII, IX and XII), a decrease in protein $\mathrm{S}$ levels and inhibition of fibrinolysis. Specifically, PT and INR testing is used to monitor vitamin $\mathrm{K}$-dependent factors $\mathrm{II}, \mathrm{V}, \mathrm{VII}$, and $\mathrm{X}$ and is most commonly used for patients on warfarin. ${ }^{2}$ Testing of a PTT was designed to assess factors VIII, IX and XI for patients either with factor deficiency or on heparin therapy. As gestation progresses, there is also a significant fall in the activity of activated protein $\mathrm{C}$, an important anticoagulant. ${ }^{3,4}$ Other plasma factors and platelet count do not change so remarkably. One of the coagulopathy seen in pregnancy is disseminated intravascular coagulation. DIC was first observed in 1901 by De Lee ${ }^{5}$ in patients of placental abruption and IUD due to hypofibrinogenemia; same explained by Jecko Thacil ${ }^{6}$ in late pregnancy, fibrinogen levels are typically 300 to $600 \mathrm{mg} / \mathrm{dl} . \mathrm{In}$ DIC serum, fibrinogen levels and platelet count are reduced and FDP are high along with consumption of clotting factors. These deranged parameters cause prolongation of bleeding time, clotting time, prothrombin time and partial thromboplastin time. DIC may be associated with hypertensive disorders of pregnancy, IUD, $\mathrm{H}$ mole, septicaemia, amniotic fluid embolism. It has been suggested that intravascular coagulation is responsible for many of the manifestations of preeclamptic toxaemia and ecclampsia. ${ }^{7}$ Apart from this, obstructive microangiopathy may follow intravascular thrombi formation which may cause renal disease, renal failure and convulsions following brain involvement. Pregnancy with deranged coagulation profile included many condition like ecplampsia-preeclmpsia spectrum (hypertensive disorders of pregnancy), HELLP syndrome, Acute fatty liver of pregnanacy TTP, ITP, gestational thrombocytopenia, thrombophilias, hemophilia and von willebrand disease.

Early assessment of severity of pre-eclampsia and eclampsia is necessary to prevent complications like HELLP syndrome DIC, multiorgan failure and IVH to decreased maternal and fetal morbidity and mortality. Hence, this study was undertaken with the aim to compare the coagulation parameters of normal pregnant women and high risk pregnancy.

\section{Material and Methods}

A tertiary hospital-based comparative prospective study was conducted for a period of one year from may 2008 to may 2009. Total 230 cases were taken and divided into 3 groups. All antenatal cases were unbooked with no antenatal visits. Group-1 comprised of 36 cases of normal pregnant women. Group-2 contained 186 cases of pregnancy at high risk with and with increased risk coagulation derangements. Group-3 comprised non-pregnant women. All pregnancy cases in second and third trimester of pregnancy were taken. All patients from the Department of Obstetrics and Gynaecology MLN medical college, a tertiary care centre of North India, were enrolled for the study.

\section{Groups Division}

\section{Group 1: Normal pregnant women}

Group 2: Pregnant women at high risk

\section{Group 3: Non-pregnant healthy women}

Ethical clearance was obtained from the Institutional Ethics Committee for conducting the study. Details of the study were explained to the subjects and written informed consent was taken from all the study subjects.

The coagulation parameters such as BT, CT, , PT, aPTT, platelet count in all pateints and serum fibrinogen levels required for the study were carried out in laboratory under Department of Pathology of same hospital in a tertiary care centre of North India.

To study the following parameters were considered in antenatal women:

- Bleeding time (normal range : 1 to 9 minutes)

- Clotting Time (normal range : 8-15 minutes)

- Activated partial Thromboplastin time (normal range 30-40 seconds)

- Prothrombin time, INR( normal range INR below 1.1)

- Platelet count( between $150,000 / \mu \mathrm{L}-400,000 / \mu \mathrm{L})$

- Serum fibrinogen levels (normal range $300-600 \mathrm{mg} / \mathrm{dl}$ )

- Anaemia grading according to WHO classification

Age and parity of pregnant women were also taken into account.

Table I.Distribution of study groups

\begin{tabular}{|c|c|c|}
\hline Groups & Number & Percentage \\
\hline Group-1 & 36 & 15.65 \\
\hline Group-2 & 186 & 80.86 \\
\hline Group-3 & 8 & 3.47 \\
\hline total & 230 & 100 \\
\hline
\end{tabular}


Table below shows division of cases according to group allocation.

Age and Parity Distribution are given in Following Tables

Table 2.Distribution of cases according to age group

\begin{tabular}{|c|c|c|}
\hline Age (years) & number & percentage \\
\hline $18-23$ & 62 & 26.95 \\
\hline $24-29$ & 120 & 52.17 \\
\hline $30-35$ & 48 & 20.86 \\
\hline & 230 & 100 \\
\hline
\end{tabular}

Table 3.Distribution of cases according to parity of women

\begin{tabular}{|c|c|c|}
\hline parity & number & perecntage \\
\hline 0 (primi) & 10 & 4.34 \\
\hline $1-3$ & 35 & 15.21 \\
\hline $4-6$ & 174 & 75.65 \\
\hline$>6$ & 11 & 4.78 \\
\hline & 230 & 100 \\
\hline
\end{tabular}

\section{Selection Criteria}

- Age: 18-35 years.

- (Group-1) pregnant women in second and third trimester with normal antenatal examination and investigation.

- (Group-2) pregnant women in second and third trimester, which were at high risk of complication and increased maternal or fetal morbidity and mortality. Group-2 cases were further distributed according to diagnosis to specify and co -relate the results accordingly.

Following table shows the distribution of group-2 according to diagnosis.

Table 4.Distribution according to diagnosis of group-2

\begin{tabular}{|c|c|c|}
\hline Diagnosis & number & percentage \\
\hline Eclampsia & 20 & 10.75 \\
\hline HELLP syndrome & 6 & 3.22 \\
\hline Pre-eclampsia & 18 & 9.67 \\
\hline PIH & 37 & 19.89 \\
\hline Placenta previa & 10 & 5.37 \\
\hline Placental abruption & 6 & 3.22 \\
\hline Preterm labour & 20 & 10.75 \\
\hline Anaemia(only) & 40 & 21.50 \\
\hline $\begin{array}{c}\text { Hyperemesis } \\
\text { gravidarum }\end{array}$ & 3 & 1.61 \\
\hline
\end{tabular}

\begin{tabular}{|c|c|c|}
\hline IHCP & 5 & 2.68 \\
\hline Other( unclassified) & 21 & 11.29 \\
\hline Total & 186 & 100 \\
\hline
\end{tabular}

- Group-3: Non-pregnant healthy women with any parity without bleeding disorders.

- Cases with all normal parameters of normal coagulation profile as per given normal range were considered as normal coagulation.

- Cases with any one or more than one parameters of coagulation which were not in given normal range were considered as deranged coagulation profile.

- Gestational age estimation done by dates and ultrasound accordingly.

- Non-pregnant women taken after ruling out pregnancy and any bleeding disorders.

\section{Result}

\section{Group- I}

Out of 36 cases in this group, 2 cases (5.5\%) had thrombocytopenia between 100,000 / and 150,000 / with all other parameters normal. In both cases, there was isolated thrombocytopenia with examination and all other routine investigations were normal. The diagnosis of gestational thrombocytopenia was made (Table 5).

Table 5.Distribution of group- I according to coagulation profile

\begin{tabular}{|c|c|c|c|c|c|}
\hline \multirow{2}{*}{ Number } & \multicolumn{2}{|c|}{$\begin{array}{c}\text { Cases with } \\
\text { normal } \\
\text { coagulation } \\
\text { profile }\end{array}$} & \multicolumn{2}{|c|}{$\begin{array}{c}\text { Cases with } \\
\text { deranged } \\
\text { coagulation } \\
\text { profile }\end{array}$} \\
\cline { 3 - 6 } & number & $\begin{array}{c}\text { perce- } \\
\text { ntage }\end{array}$ & number & $\begin{array}{c}\text { perce- } \\
\text { ntage }\end{array}$ \\
\hline $\begin{array}{c}\text { Group } \\
-1\end{array}$ & 36 & 34 & 94.44 & 2 & 5.55 \\
\hline
\end{tabular}

\section{Group-2}

Out of 186 cases in this group, 31 cases (16.66\%) had deranged coagulation profile. Out of these cases, 7 cases of eclampsia were having derangements. Three cases of eclampsia were also having sever anaemia with thrombocytopenia, 4 cases of eclampsia had mild to moderate anaemia with increased clotting time with INR more than 1.1 in 3 cases and thrombocytopenia in one case. Next diagnosis was HELLP syndrome in all cases with thrombocytopenia, 5 cases with platelet counts below 100,000/ $\mu \mathrm{L}$. As diagnosis suggests, all were having anaemia and increased liver enzymes with haemolysis with prolong BT,CT and INR . Four cases had decreased serum fibrinogen and increased FDP diagnosed as in disseminated intravascular coagulation. 
Three cases of pre-eclampsia had thrombocytppenia with 1 case with prolong aPTT and INR, 2 cases ot PIH and 1 case of palcenta previa were having thrombocytopenia with increased PT 4 cases of sever anaemia had isolated thrombocytopenia. 2 cases of placental abruption had all parameters deranged and DIC with decresed levels of serum fibrinogen and increased FDP. 1 case of preterm labor had thrombocytopenia. Out of 5 unclassified( other) cases 3 cases were HIV positive with 2 cases with jaundice, 1 case of heart disease ( RHD) and 1 case of chronic liver disease with jaundice.
Series $\mathbf{1}=$ normalcoagulation profile

Series $\mathbf{2}$ = derranged coagualtion profile

\section{Pregnancy Outcome}

In terms of pregnancy outcome, maternal and perinatal mortality took adverse outcome. Adverse maternal and perinatal outcome was seen in group-2. In group 1 and Group-3, there was no maternal or perinatal mortality .

\section{Group 2}

Maximum maternal and perinatal mortality was seen in

Table 6.Distribution of group-2 according to coagulation profile

\begin{tabular}{|c|c|c|c|c|c|}
\hline \multirow{2}{*}{} & \multirow{2}{*}{ Number } & \multicolumn{2}{|c|}{$\begin{array}{c}\text { Cases with normal coagulation } \\
\text { profile }\end{array}$} & \multicolumn{2}{c|}{$\begin{array}{c}\text { Cases with deranged coagulation } \\
\text { profile }\end{array}$} \\
\cline { 3 - 6 } & & number & percentage & number & percentage \\
\hline Group-2 & & & & 7 & 35 \\
\hline Eclampsia & 20 & 13 & 65 & 6 & 100 \\
\hline HELLP syndrome & 6 & 0 & 0 & 3 & 16.66 \\
\hline Pre-e clampsia & 18 & 15 & 83.33 & 2 & 5.40 \\
\hline PIH & 37 & 35 & 94.59 & 1 & 10 \\
\hline Placenta previa & 10 & 9 & 90 & 2 & 33.33 \\
\hline Placental abruption & 6 & 4 & 66.66 & 1 & 5 \\
\hline Preterm labor & 20 & 19 & 95 & 4 & 10 \\
\hline Anaemia & 40 & 36 & 90 & 0 & 0 \\
\hline Hyperemesis gravidarum & 3 & 3 & 100 & 0 & 0 \\
\hline IHCP & 5 & 5 & 100 & 5 & 23.80 \\
\hline Other & 21 & 16 & 76.19 & 31 & 16.66 \\
\hline Total & 186 & 155 & 83.33 & & \\
\hline
\end{tabular}

In this group, maximum cases with deranged coagulation profile were from hypertensive disorders of pregnancy, followed by anaemia, placental abruption and jaundice.

\section{Group-3}

All cases had normal coagulation profile.

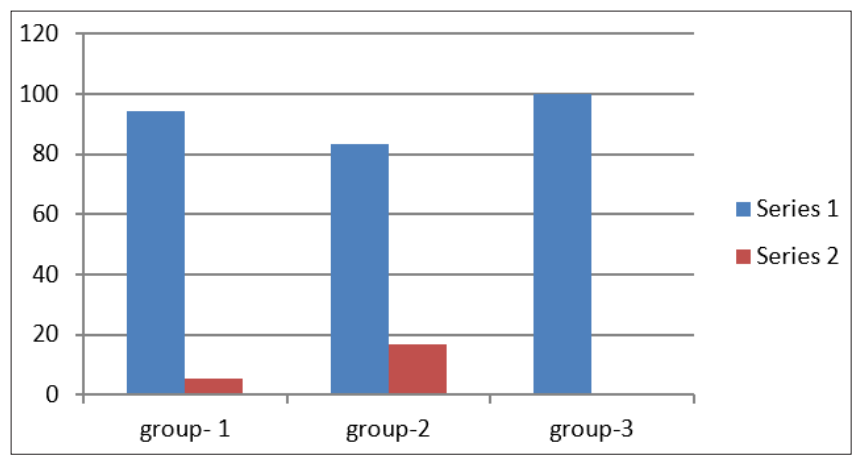

Chart I.Distribution according deranged coagulation profile in groups eclampsia cases; there were 5 maternal deaths (25\%) and 7 perinatal deaths (35\%) in eclampsia cases. Out of 5 cases, 3 had IVH (60\%) at presentation and 2 had pulmonary oedema with multiorgan failure. Out of 7 perinatal deaths, 2 were fresh IUD at presentation and 4 perinatal deaths due to prematurity and FGR with 2 cases of meconium stained liquor. One perinatal death was due to prematurity with septicaemia. In HELLP syndrome cases, 2 maternal deaths (33.3\%), one presented in DIC and developed PPH in third stage, second with severe anaemia and DIC with multiorgan failure. Two perinatal deaths (33.3\%) occurred in HELLP syndrome cases both with FGR and one with septicaemia. In placenta previa cases, there were 2 maternal deaths (20\%), one presented with $\mathrm{APH}$ with severe anaemia went into cardiac failure. Second case with placenta previa died due to PPH with cardiac failure even after subtotal hysterectomy. Two perinatal deaths (20\%) occurred in placeneta previa cases due to FGR and prematurity. Rest of the 2 cases of maternal deaths were 1 case (2.5\%) of severe anaemia in failure and 1 case of jaundice with septicaemia with MODS. 
In perinatal mortality, rest of cases were 3 cases (15\%) of preterm labor, 2 cases of severe anaemia with FGR, 1 case of HIV positive mother with FGR and oligo, 1 FGR septicaemia and 2 cases with meconium aspiration syndrome.

Total maternal mortality and perinatal mortality were $4.96 \%$ and $10.26 \%$ respectively in cases with deranged coagulation profile. Here, maximum cases with adverse outcome were of eclampsia, HELLP syndrome, severe anaemia and PPH due to DIC. Maximum perinatal deaths were due to maternal complications, prematurity, FGR .all perinatal moratlity associated with placenta previa and abrution were associated with FGR. time ratio were shorter, and platelet count decreased gradually during pregnancy, with no change in mean platelet volume; conditions during pregnancy which cause deranged coagulation can lead to adverse maternal and perinatal outcome. Hypertensive disorder like preeclampsia is an idiopathic multisystem disorder specific to human pregnancy and the puerperium. Hematological abnormalities such as thrombocytopenia and decrease in some plasma clotting factors may develop in pre-eclamptic women. Subtle change suggesting Disseminated Intravascular Coagulation (DIC) is one of the serious outcome of coagulation disorders. Thus, coagulation testing is to be done in these patients to rule out

Table 6.Distribution of groups according to pregnancy outcome

\begin{tabular}{|c|c|c|c|c|c|}
\hline \multirow{2}{*}{ Groups } & \multirow{2}{*}{ number } & \multicolumn{2}{|c|}{ Maternal mortality } & \multicolumn{2}{c|}{ Perinatal mortality } \\
\cline { 3 - 5 } & & number & perecntage & Number & Percentage \\
\hline Group-1 & 36 & 0 & 0 & 0 & 0 \\
\hline Group-2 & & & & & \\
\hline eclampsia & 20 & 5 & 25 & 7 & 35 \\
\hline HELLP syndrome & 6 & 2 & 33.33 & 2 & 33.33 \\
\hline Pre-eclampsia & 18 & 0 & 0 & 2 & 11.11 \\
\hline PIH & 37 & 0 & 0 & 0 & 0 \\
\hline Placenta previa & 10 & 2 & 20 & 2 & 20 \\
\hline Placenta abruption & 6 & 0 & 0 & 1 & 16.66 \\
\hline Preterm labor & 20 & 0 & 0 & 3 & 15 \\
\hline anaemia & 40 & 1 & 2.5 & 2 & 5 \\
\hline Hyperemesis gravidarum & 3 & 0 & 0 & 0 & 0 \\
\hline IHCP & 5 & 0 & 0 & 1 & 20 \\
\hline other & 21 & 1 & 5 & 4 & 20 \\
\hline total & 222 & 11 & 4.95 & 24 & 10.81 \\
\hline
\end{tabular}

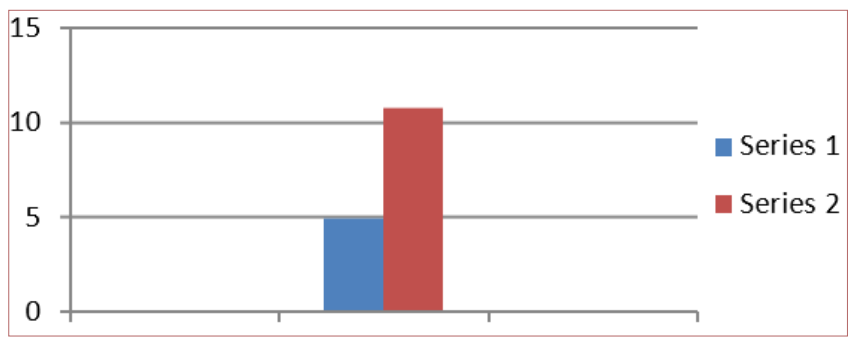

Chart 2.Series I = maternal mortality, series $\mathbf{2}=$ perinetal mortality in persentage

\section{Discussion}

Pregnancy is associated with specific changes in coagulation profile to reduce, compensate and decrease blood loss during delivery. In our study, there were 2 cases of isolated thrombocytopenia in contrast to a study. ${ }^{8}$ where prothrombin time, international normalized ratio, activated partial thromboplastin time, and activated partial thromboplastin
DIC and HELLP syndrome. In our study, thrombocytopenia was most common finding in all coagulation parameters followed by increased PT. Cases with complicated DIC had all parameters deranged. In their studies, Leduce et al9 found that thrombocytopenia is a good predictor of outcome overall coagulation profile. Same finding were described by FitzGerald et al. ${ }^{10}$ in their study. In a study, Jahromi et al. ${ }^{11}$ concluded that an abnormal platelet count or aPTT is detected in a patient with severe preeclampsia, a coagulopathic disorder should be clinically suspected. In contrast, Miall et et al. ${ }^{12}$ in their study found PT and aPTT are better predictors of overall coagulation profile. In our study, $60 \%$ of maternal mortality in eclampsia had IVH due to deranged coagulation which is a significant finding.

In terms of perinatal outcome, maximum cases of deranged coagulation had FGR and maximum perinatal mortality was due to FGR and prematurity. Ananth et al. ${ }^{13}$ and Kramer et al. ${ }^{14}$ in their study found increased FGR in placental 
abruption. In comparision to our study Saibai et al. ${ }^{15}$ in their study of deranged coagulation and DIC in pregnancy described higher rates of the maternal and perinatal mortality, $13 \%$ and $34 \%$, respectively and $72 \%$ of births were preterm. Meshram et al. ${ }^{16}$ concluded there was no significant variation in coagulation with normal pregnant group and preeclampsia. They found much higher rates of adverse maternal and perinatal outcome as compared to our study because of more cases with DIC. ${ }^{16}$ In some recent studies, other parameters to diagnose deranged coagulation are studied. In a similar study, thrombin time and mean platelet volume were found good for early monitoring of severity of preeclampsia. ${ }^{17}$

\section{Conclusion}

Normal late pregnancy shows a physiological hypercoagulable state. Coagualtion disorder in pregnancy can be any of spectrum, hypercoaguble state to haemorrhgic tendencies. In this study, no case of abnormal hypercoaguble state was found. In cases of haemorragic tendencies DIC is most significant and in terms of management it still remained a challenge. So, early assessment and prediction of such adverse complications very important. In our study, we concluded that derranged coagulation profile is a significant predictor of increased adverse maternal and perinatal outcome. Apart from pre-eclmpsia and eclampsia spectrum, other cases with even isolated thrombocytopenia should be thoroughly investigated and followed closely to prevent complications and adverse pregnancy outcome. Though some recent studies also concluded other parameters, but basic parameters as studied by the investigators remained useful even in health setups and facilities below tertiary level where patient can be referred to higher centres accordingly if needed.

\section{Conflict of Interest: None}

\section{References}

1. Thornton P, Douglas J. Coagulation in pregnancy. Best Practice \& Research Clinical Obstetrics and Gynaecology 24(2010): 339-352.

2. Katz D, Beilin Y. Disorders of coagulation in pregnancy. British Journal of Anaesthesia 2015; 115: ii75-ii88.

3. Bremmemd KA. Haemostatic changes in pregnancy. 2003; 153-168.

4. Buseri FI, Jeremiah ZA, Kalio FG. Influence of Pregnancy and Gestation Period on Some Coagulation Parameters among Nigerian Antenatal Women. Research Journal of Medical Sciences 2008; 2: 275-281.

5. DeLee JB. A case of fetal hemorrhagic diatheses with premature detachment of the placenta. Am J Obstet Gynecol 44: 785.

6. Namavar Jahromi B, Rafieelranian SH. Red Crescent Medical Journal. IRCMJ 2009; 11(3): 321-324. CIranian
Red Crescent Medical Journal.

7. McKay DG. GertMüllerMD, Berghaus MD. Therapeutic implications of disseminated intravascular coagulation. 1967; 392-410.

8. Xing- hui liua, yong-mei et al. Prospective sequential study of coagulation changes during pregnanacy in Chinese women; 2009; 105(3): 240-243.

9. Leduc line md, Wheeler, James m. md, Mph, Kirshon, Brian md, Mitchell, Patricia md, Cotton, david b. md (C) 1992 The American College of Obstetricians and Gynecologists.

10. Mary Pat Fitz. Gerald Screening for consumptive coagulopathy in preeclampsia. International Journal of Gynecology \& Obstetrics 46(1): 3-9. August 1994

11. Thachila J, Cheng-Hock Toh, Thachil J, Toh $\mathrm{CH}$. Disseminated intravascular coagulation in obstetric disorders and its acute haematological management. Blood Reviews 2009; 23: 167-176.

12. Jahormi BN, Rafiee SH. Coagulation factors in sever preeclampsia. Iran red C J 2009; 11(3); 321-324.

13. Miall FM, Deol P, Barnes TA, Dampier K, Watson CC, Oppenheimer CA, Pasi KJ, Pavord SR. Coagulation status and complications of pregnancy. Thromb Res 2005; 115(6): 461-467.

14. Ananth CV, Berkowitz GS, Savitz DA, Lapinski RH.Placental abruption and adverse perinatal outcomes. 1999; 282(17): 1646-51.

15. Kramer MS, Usher RH, Pollack R, Boyd M, Usher S. Etiologic determinants of abruptio placentae. Obstet Gynecol 1997; 89(2): 221-226.

16. Sibai BM, Amdan R. Acute renal failure in pregnancy complicated by haemolysis, elevated liver enzyme and low platelets count. J Obstet Gynecol 1990; 162; 311-316.

17. Meshram DP. Maternal and foetal outcomes in Pregnancy Induced Hypertension -A hospital based study. International Journal of Pharmaceutical Science Invention 2319-6718.

18. Lei Han, Xiaojie Liu, Hongmei Li. Blood Coagulation Parameters and Platelet Indices: Changes in Normal and Preeclamptic Pregnancies and Predictive Values for Preeclampsia 2014; 9(12): e114488. 